www.jmscr.igmpublication.org

Index Copernicus Value: 79.54

ISSN (e)-2347-176x ISSN (p) 2455-0450

crossref DOI: https://dx.doi.org/10.18535/jmscr/v7i4.37

\title{
Carcinoma Breast- A Relationship between the Tumor Size, Number of Lymph Nodes and Metastasis
}

\author{
Authors \\ Man Singh Bairwa ${ }^{1}$, Ganpat Singh Choudhary ${ }^{2}$, Bharti Saraswat $^{*}$ \\ ${ }^{1}$ Senior Resident Doctor, ${ }^{2,3}$ Professor \\ Department of General Surgery, Dr S N Medical College, Jodhpur (Rajasthan) \\ *Corresponding Author \\ Bharti Saraswat \\ Professor, Department of General Surgery, Dr S N Medical College, Jodhpur (Rajasthan), India
}

\begin{abstract}
Background: World-wide breast cancer is the most frequent type of cancer among females with increasing incidence.

Methods: This study was retrospective and prospective both. Total 40 Female patients of Breast cancer, from all age group admitted in Department of Surgery, Dr. S.N. Medical College, Jodhpur were included.

Results: As the average size of the breast tumor increased, so did the average number of axillary lymph nodes both clinically as well as Histopathologically positive for metastasis. Conversely more the number of axillary lymph nodes (both clinically and histopathological) larger was the size of the tumor.

Conclusion: The study contains 40 cases of breast carcinoma and it reveals that as the size of breast tumor increases, so does the average lymph node number increases.(both clinically and Histopathologically positive for metastasis).

Keywords: Breast Carcinoma, Histopathologically Positive, Metastasis.
\end{abstract}

\section{Introduction}

World-wide breast cancer is the most frequent type of cancer among females with increasing incidence. In India, it is the second most prevalent cancer in females after cancer of cervix. The exact cause of breast cancer is not known but certain epidemiologic factors influence its occurrence and predispose to it. Once thought to be a local or regional disease, breast cancer is now considered a systemic disease in which micro metastasis may have disseminated long before the primary tumour is detected.
The various etiological and predisposing factors for breast cancer are Genetic, Dietary, Hormonal, Obesity, Radiation, Environmental etc.

Two of the most important prognostic indicators in breast cancer are tumour size and the axillary lymph node status; the size of tumour directly correlating with the probability of nodal metastasis i.e. patients with large breast masses or higher clinical stage is more likely to have positive nodes. Node positive patient experiences relapses usually in distant organs and tissues mainly in bones, lungs, pleura, liver and soft tissues. It is sometime seen that the clinically 
palpable axillary nodes often turn out to be nonmetastatic and clinically non-palpable nodes may be found to be positive for metastasis. Evaluation of axillary lymph node status is thus an important prognostic factor depending on pathological staging rather than clinical assessment alone. There is also proved a strong correlationship between the size of tumor and the probability of distant metastasis. ${ }^{3}$

The present study carried out to draw a relationship between the tumor size, number of lymph nodes and metastasis.

\section{Material and Methods}

Source of Data: Female patients of Breast cancer, from all age group admitted in Department of Surgery, Dr. S.N. Medical College, Jodhpur.

Sample Size: A total of 40 patients.

\section{Inclusion Criteria}

- All age group.

- Female patients.

- Patients with proven malignancy.

\section{Exclusion Criteria}

- Male patients with breast carcinoma.

- Patients with breast lumps other than carcinoma, proved by history, examination and histopathology.

Study Duration: January 2016 - December 2016 (Retrospective)

January 2017 - October 2017(Prospective)

Study Design: Prospective and Retrospective.

\section{Data Collection}

1. Inclusion and exclusion criterias were applied to surgical patients admitted to Dr.

S. N. Medical College and Associated Hospitals.

2. Patients were educated about the study and only those patients consenting to participate in the study were included.
3. The evaluation was include, history, local and systemic examination to search for the metastasis of the disease.

4. The retrospective study was based on case records of all the patients of Breast cancer admitted in various surgical wards of department of surgery, Dr. S.N. Medical College Jodhpur.

5. The cases included in the prospective study were personally attended and all relevant data recorded.

6. Diagnosis was established by FNAC, Trucut (Core-cut) or Open Biopsy and HPE.

7. The patient was subjected to various investigation including- Routine, USG Breast and Axilla, Mammography and Specific to find out any metastasis which will include X-ray Chest, Dorsal Spine, pelvis, USG Abdomen and pelvis, ,CECT, Abdomen and pelvis, HRCT- Thorax and MRI Spine if required.

All these finding were used to establish the final stage of disease.

\section{Data Analysis}

Data was analyzed using SPSS software version 20. Descriptive statistics was calculated using frequencies and percentages. Association was calculated using Chi-square test and Yates correction was used wherever required.

\section{Observations}

The following observations are based on a study conducted on 40 cases of breast cancer patients admitted in various surgical units of Dr. S.N. Medical College, Jodhpur and attached group of Hospitals to establish correlation between tumor size, axillary lymph nodes and metastasis. 


\section{AGE DISTRIBUTION}

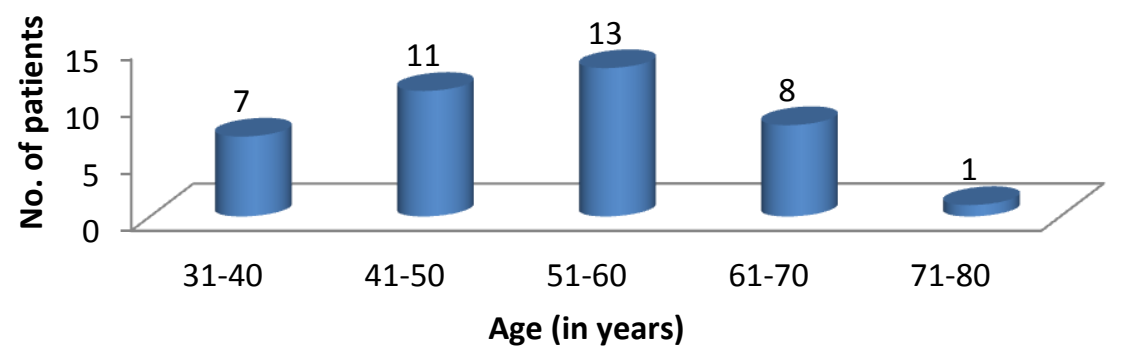

In this study, the incidence is higher in $4^{\text {th }}, 5^{\text {th }}$ and $6^{\text {th }}$ decade.

Table 1: Distribution of Symptoms

\begin{tabular}{|l|c|c|}
\hline Symptoms & No. of patients & Percentage \\
\hline Lump & 40 & 100 \\
\hline Pain & 25 & 62.5 \\
\hline Nipple discharge & 4 & 10 \\
\hline Nipple retraction & 7 & 17.5 \\
\hline Skin ulceration & 1 & 2.5 \\
\hline
\end{tabular}

Lump was presenting feature in all cases $100 \%$. The next most common presenting feature was pain, which was present in $62.5 \%$ cases. $10 \%$,
$17.5 \%$ and $2.5 \%$ cases had nipple discharge, nipple retraction and skin ulceration.

Table 2: Site of Carcinoma within Breast

\begin{tabular}{|l|c|c|}
\hline Quadrant & No. of patients & Percentage \\
\hline Upper outer & 17 & 42.5 \\
\hline Upper Inner & 6 & 15 \\
\hline Lower outer & 3 & 7.5 \\
\hline Lower Inner & 0 & 0 \\
\hline Central & 2 & 5 \\
\hline Diffuse & 12 & 30 \\
\hline
\end{tabular}

In majority of patients i.e. the tumor was present diffuse variety include UO+UI, Cen+UO+UI, in the upper outer quadrant followed by upper Cen+UO and Cen.+UI. inner quadrant, lower outer and central sector. In

Table 3: Breast Affected

\begin{tabular}{|l|c|c|}
\hline Histopathology & No. of patients & Percentage \\
\hline Infiltrating duct carcinoma (NOS) & 39 & 97.5 \\
\hline Infiltrating lobular carcinoma & 1 & 2.5 \\
\hline
\end{tabular}

In the present study $97.5 \%$ of the cases were infiltrating duct carcinoma (NOS).

Table 4: Axillary Lymph Node (Histo-Positive and Negative)

\begin{tabular}{|l|c|c|}
\hline Axillary lymph nodes & Histo-Positive & Histo-Negative \\
\hline Clinical palpable $(\mathrm{n}=24)$ & $21(87.5 \%)$ & $3(12.5 \%)$ \\
\hline Clinical non palpable $(\mathrm{n}=16)$ & $14(87.5 \%)$ & $2(12.5 \%)$ \\
\hline
\end{tabular}

In the present study, lymph nodes were palpable in $60 \%$ cases of which $87.5 \%$ were histo-positive for metastasis and $12.5 \%$ were histo-negative.
$40 \%$ cases had no node palpable clinically of which $87.5 \%$ were histo-positive and $12.5 \%$ were histo-negative for metastasis. 
Table 5: Relation between Tumor Size and Lymph Nodes (Clinical)

\begin{tabular}{|l|c|c|c|}
\hline Tumor size $(\mathrm{cm})$ & $\begin{array}{c}\text { No. of } \\
\text { patients }\end{array}$ & $\begin{array}{c}\text { Average clinical } \\
\text { size }(\mathrm{n} \mathrm{cm})\end{array}$ & $\begin{array}{c}\text { Average clinical lymph } \\
\text { node number }\end{array}$ \\
\hline$\leq 2$ & 2 & 2 & 0 \\
\hline$>2-5$ & 23 & 4.34 & 1.13 \\
\hline$>5$ & 15 & 7.13 & 2.4 \\
\hline
\end{tabular}

Table 6: Relation between Tumor Size and Lymph Nodes (HPE Positive)

\begin{tabular}{|l|c|c|c|}
\hline $\begin{array}{l}\text { HPE Tumor size } \\
(\mathrm{cm})\end{array}$ & $\begin{array}{c}\text { No. of } \\
\text { patients }\end{array}$ & $\begin{array}{c}\text { Average HPE size } \\
\text { (in } \mathrm{cm})\end{array}$ & $\begin{array}{c}\text { Average positive HPE } \\
\text { lymph node number }\end{array}$ \\
\hline$\leq 2$ & 8 & 2 & 3.25 \\
\hline$>2-5$ & 27 & 4.05 & 3.92 \\
\hline$>5$ & 5 & 6.4 & 8.8 \\
\hline
\end{tabular}

The relation between the size of the tumor and average number of lymph nodes (CLINICAL and number of axillary lymph nodes. As the average HPE) also increase. size of tumor increases (CLINICAL and HPE) the

Table 7: Relation between Number of Lymphnode and Tumor Size (Clinical)

\begin{tabular}{|l|c|c|}
\hline $\begin{array}{l}\text { Axillary lymph node } \\
\text { number (clinical) }\end{array}$ & Percentage & $\begin{array}{l}\text { Average (clinical) } \\
\text { size of tumor }(\mathrm{cm})\end{array}$ \\
\hline 0 & 40 & 4.25 \\
\hline 1 & 7.5 & 5 \\
\hline 2 & 22.5 & 5.55 \\
\hline 3 & 20 & 5.87 \\
\hline$>3$ & 10 & 7.75 \\
\hline
\end{tabular}

Table 8: Relation between Number of Lymph Nodes and Tumor Size (HPE Positive)

\begin{tabular}{|l|c|c|}
\hline $\begin{array}{l}\text { Axillary lymph node } \\
\text { number (HPE) }\end{array}$ & Percentage & $\begin{array}{c}\text { Average tumor size - } \\
\text { Positive HPE (in cms) }\end{array}$ \\
\hline 0 & 12.5 & 3.2 \\
\hline $1-5$ & 55 & 3.95 \\
\hline $6-10$ & 27.5 & 4.18 \\
\hline$>10$ & 5 & 4.25 \\
\hline
\end{tabular}

The relation between number of lymph nodes nodes increase so does the average size of the (CLINICAL and HPE) and the size of the tumor tumor increase clinically as well as HPE.

(CLINICAL and HPE). As the number of lymph

Table 10: TNM Staging

\begin{tabular}{|l|c|c|c|c|}
\hline Tumor size (T) & T1 & T2 & T3 & T4 \\
\hline Number of cases & 0 & 26 & 14 & 0 \\
\hline Nodal status (N) & N0 & N1 & N2 & N3 \\
\hline Number of cases & 16 & 19 & 5 & 0 \\
\hline Metastasis (M) & M0 & M1 & - & - \\
\hline Number of cases & 40 & 0 & - & - \\
\hline
\end{tabular}

\begin{tabular}{|l|c|c|}
\hline TNM STAGE & No. of cases & Percentage \\
\hline 0 & 0 & 0 \\
\hline I & 0 & 0 \\
\hline IIA & 14 & 35 \\
\hline IIB & 13 & 32.5 \\
\hline IIIA & 13 & 32.5 \\
\hline IIIB & 0 & 0 \\
\hline IIIC & 0 & 0 \\
\hline IV & 0 & 0 \\
\hline
\end{tabular}

In the present study, by TNM staging $67.5 \%$ cases were in stage II and $32.5 \%$ cases were in stage III. 


\section{Discussion}

The main route of spread of breast cancer is by way of the axilla. The presence or absence of palpable lymph nodes within the axilla represents one of the important criteria for clinical staging.

Two of the most important prognostic determinants of breast cancer are the number of axillary lymph nodes and the size of the breast tumor. Although the histologic grading of malignancy and clinical staging are comparable from prognostic standpoint, a more accurate prediction in this regard may be obtained when both are considered.

A study of the correlation between the size of the tumor, number of positive axillary lymph nodes and metastasis is presented herewith carried out on 40 patients admitted in various surgical units of Dr. S.N. Medical College, Jodhpur from January 2016 to October 2017.

Hisotpathology of the specimens revealed that in $97.5 \%$ of the cases, the lesion was infiltrating duct carcinoma (NOS) of the breast in this study. Infiltrating lobular carcinoma was present in 1 case $(2.5 \%)$. Similar frequency was observed by Srivastava et al (1976) and Baptist et al (1973), S. Miller (1989) in this series found that $88.5 \%$ tumors were infiltrating duct carcinoma type $8.4 \%$ were infiltrating lobular type and $3.1 \%$ were in situ ductal type. M. Merson et al (1992) observed that invasive ductal carcinoma was most common (73\%) followed by invasive lobular carcinoma in $8 \%$ cases. $^{2-5}$

In the present series $57.5 \%$ cases clinically presented with tumor size ranging from $>2-5 \mathrm{~cm}$. $37.5 \%$ cases with tumor $>5 \mathrm{~cm}$ and $5 \%$ cases with tumor $<2 \mathrm{~cm}$. K. Joshi $(1983)^{6}$ and Virginia et al $(1982)^{7}$ had the same experience. On the contrary R.K. Garg et al (1982) ${ }^{8}$ reported few cases with tumor size $<5 \mathrm{~cm}$. in this study $30 \%$ cases had tumor size $5 \mathrm{~cm}$. diameter followed by sizes of 7.5 and $10 \mathrm{~cm}$. in $29 \%$ and $23 \%$ cases respectively. Clinically palpable ipsilateral axillary lymph nodes were found in $60 \%$ cases. Fraser $(1977)^{9}$ said that clinical examination is inaccurate in assessing the significance of axillary lymph nodes; about $26 \%$ of the patients with no palpable lymph nodes have histological evidence of involvement with metastasis and a greater percentage of the patients with palpable nodes have no evidence of metastasis. In our study among the 24 cases with clinically palpable lymph nodes, $87.5 \%$ were histologically positive for metastasis and $12.5 \%$ were histologically negative for metastasis and among 16 cases without any clinically palpable lymph nodes $87.5 \%$ were positive for metastasis while $12.5 \%$ were negative for metastasis.

In the present study the maximum number of patients $60 \%$ had palpable lymph nodes, $40 \%$ had no lymph nodes palpable clinically, 1 lymph node palpable in $7.5 \%$ cases, 2 lymph nodes palpable in $22.5 \%$ cases, 3 lymph nodes palpable in $20 \%$ cases while in $10 \%$ cases had >3 lymph nodes palpable clinically.

The number of lymph nodes dissected from the specimen varied. In $12.5 \%$ it was reported $0-5$ lymph nodes, in $47.5 \%$ cases 6-10 lymph nodes dissected and in $40 \%$ cases 10 or $>10$ lymph nodes were dissected from the specimen.

The number of lymph nodes, which were positive for metastasis on histo-pathological examination, was as follows. In $12.5 \%$ cases, no lymph node was found to be positive for metastasis, in $55 \%$ cases 1-5 lymph nodes were positive. In $27.5 \%$ cases 6-10 lymph nodes and in only 5\% cases 10 or more than 10 lymph nodes were positive for metastasis. In 1980 S. Pal and S.K. Sengupta ${ }^{10}$ also found that $60 \%$ of the patients presented with a lump in breast with significant axillary lymph nodes. Haagensen $(1986)^{11}$ reported axillary metastasis in $70 \%$ cases.

In the present study it was found that as the average size of the tumor increases, so does the average of lymph nodes increases both clinically as well as Histopathologically positive for metastasis. In this series it was seen that for tumors less than $2 \mathrm{~cm}$ or $2 \mathrm{~cm}$ average size $2 \mathrm{~cm}$ (in both clinically/HPE), the average number of positive lymph node was zero (clinically), 3.5 (HPE). For tumor $>2-5 \mathrm{cmwith}$ an average being 
size $4.34 \mathrm{~cm}$ (clinically) and $4.04 \mathrm{~cm}$ (HPE), the average number of lymph nodes were found to be 1.13 clinically and 3.92 on the HPE. For tumor 5 $\mathrm{cm}$ or $>5 \mathrm{~cm}$. with an average being $7.13 \mathrm{~cm}$ (clinically) and $6.4 \mathrm{~cm}$ (HPE), the average number of lymph node obtained was 2.4 and 8.8 respectively. A similar correlation between tumor size and lymph nodes was also observed by Koscielny, Tubina et al (1984) ${ }^{12}$.

Conversely a relation was tried to be derived by first grouping the number of lymph nodes and then finding out the average size of the tumor. It was seen that as the number of lymph nodes increased so did the size of the tumor by both clinical and HPE increases.

\section{Conclusion}

The study contains 40 cases of breast carcinoma and it reveals that as the size of breast tumor increases, so does the average lymph node number increases. (both clinically and Histopathologically positive for metastasis).

\section{Bibliography}

1. Baker R. Robinson: Preoperative assessment of patients with breast cancer. The surgical clinics of North America 64/6, 1984.

2. Silverstein M.J. et al.: Axillary lymph node dissection for intraductal breast carcinoma. Is it indicated? Cancer 1987, May 15, 59910), 1819-24.

3. Baptist JH. The Edwin Smith Surgical Papyrus. Chicago: University of Chicago Press; 1930.p. 405.

4. Miller S. et al.: Histopathology of breast cancer in young women in relation to use of oral contraceptives. J. Clinical Path 42: 387-390, 1989.

5. Merson M.et al.: Breast cancer presenting as metastasis without evidence of a primary tumor. Cancer vol. 70(2), July 92.
6. Joshi K.et al: Pathologic profile of invasive breast cancer. Ind.J. Cancer vol.20, 15-22, 1983

7. Vieginia et al.: Unilateral breast-feeding and breast cancer. Lancet 2: 124, 1977.

8. Garg R.K et al.: Cancer of the breast five year review at Mahatma Gandhi Hospital, Jabalpur. Indian J. Surg. 6: 347-350, 1982

9. Fisher E.R. et al.: Detection and significance of occult axillary node metastasis in patients with involved breast cancer 42(4): 2025-31, Oct. 1978

10. Pal S. et al.: Breast cancer in west Bengal an epidemiological study. 1969-1972. Ind. J. Cancer 17:153-158, 1980.

11. Haagensen C.D. et al: Treatment of early mammary carcinoma. A Cooperative international study. Ann Surg 157: 157179, Feb. 1963.

12. Kosielny et al: Breast cancer - relationship between the size of the primary tumour and the possibility of metastatic dissemination. Br. J. Cancer 49: 709, 1984. 